\title{
Comparison of adverse events between video and direct laryngoscopes for tracheal intubations in emergency department and ICU patients-a systematic review and meta- analysis
}

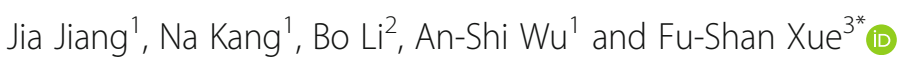

\begin{abstract}
Objective: This systematic review and meta-analysis was designed to determine whether video laryngoscope (VL) compared with direct laryngoscope (DL) could reduce the occurrence of adverse events associated with tracheal intubation in the emergency and ICU patients.

Methods: The current issue of Cochrane Central Register of Controlled Trials, PubMed, EMBASE, and Web of Science (from database inception to October 30, 2018) were searched. The RCTs, quasi-RCTs, observational studies comparing VL and DL for tracheal intubation in emergency or ICU patients and reporting the rates of adverse events were included. The primary outcome was the rate of esophageal intubation (El). Review Manager 5.3 software was used to perform the pooled analysis and assess the risk of bias for each eligible RCT. The ACROBATNRSi Cochrane Risk of Bias Tool was applied to assess the risk of bias for each eligible observational study.

Results: Twenty-three studies (13,117 patients) were included in the review for data extraction. Pooled analysis showed a lower rate of El by using $V L$ (relative risk [RR], 0.24 ; $P<0.01$; high-quality evidence for RCTs and very lowquality evidence for observational studies). Subgroup analyses based on the type of studies, whether a cardiopulmonary resuscitation study, or operators' expertise showed a similar lower rate of El by using VL compared with $\mathrm{DL}$ in all subgroups $(P<0.01)$ except for experienced operators (RR, $0.44 ; P=0.09)$. There were no significant differences between devices for other adverse events $(P>0.05)$, except for a lower incidence of hypoxemia when intubation was performed with VL by inexperienced operators $(P=0.03)$.

Conclusions: Based on the results of this analysis, we conclude that compared with $\mathrm{DL}, \mathrm{VL}$ can reduce the risk of $\mathrm{El}$ during tracheal intubation in the emergency and ICU patients, but does not provide significant benefits on other adverse events associated with tracheal intubation.
\end{abstract}

Keywords: Airway management, Laryngoscope, Tracheal intubation, Randomized controlled trial, Observational study

\footnotetext{
* Correspondence: xuefushan@aliyun.com

${ }^{3}$ Department of Anesthesiology, Beijing Friendship Hospital, Capital Medical

University, Beijing 100050, China

Full list of author information is available at the end of the article
}

(c) The Author(s). 2020 Open Access This article is distributed under the terms of the Creative Commons Attribution 4.0 International License (http://creativecommons.org/licenses/by/4.0/), which permits unrestricted use, distribution, and reproduction in any medium, provided you give appropriate credit to the original author(s) and the source, provide a link to the Creative Commons license, and indicate if changes were made. The Creative Commons Public Domain Dedication waiver (http://creativecommons.org/publicdomain/zero/1.0/) applies to the data made available in this article, unless otherwise stated. 


\section{Introduction}

Tracheal intubation is a primary lifesaving procedure for emergency department (ED) or intensive care unit (ICU) patients associated with respiratory dysfunction or decreased airway protection. Under the urgent situation, however, airway management can be challenging due to decompensated cardiopulmonary physiology, inadequate provision of tools and skilled staffs, unfasted state, simultaneous performance of cardiopulmonary resuscitation (CPR) or other medical procedures, difficult access to the patient head, and various anatomic features of difficult airways [1]. It has been reported that failure rate of urgent tracheal intubations in the ED and ICU is significantly higher compared to tracheal intubations performed in the operating room [2]. Furthermore, the results of the Fourth National Audit Project of the Royal College of Anaesthetists and the Difficult Airway Society shows that at least one in four major adverse airway events in a hospital are likely to occur in the ED or ICU and adverse airway events leading to death or brain damage are approximately 30 -fold and 60-fold more frequent in the ICU and ED than in the operating room [1]. Thus, the strategies or alternative methods to reduce the occurrence of adverse events associated with urgent tracheal intubations in the ED and ICU patients are needed.

Traditionally, tracheal intubation is performed using direct laryngoscope (DL), which requires the alignment of the oral, pharyngeal and laryngeal axes to allow direct visualization of the glottis. Thus, tracheal intubation with DL is generally regarded as a difficult skill to acquire and maintain. Video laryngoscope (VL) is a new device that contains a miniaturized camera at the blade tip to indirectly visualize the glottis. Because of proven advantages of a fast learning curve, an improved laryngeal visualization and an increased success rate, VL has been widely used for tracheal intubation in emergency and critical situations [3-22]. There have been several meta-analyses comparing VL with DL for tracheal intubation in the ED and ICU patients, but they have mainly focused on the success rate of tracheal intubation and provided different outcomes [23-29]. Most important, it is unclear whether the use of VL can reduce the adverse events associated with tracheal intubations in the ED and ICU patients. Thus, this systematic review and meta-analysis was carried out to determine whether VL compared with DL could reduce the adverse events associated tracheal intubation in the ED and ICU patients.

\section{Materials and methods}

This systematic review and meta-analysis was conducted following the recommendations of The Cochrane Handbook for Systematic Reviews of Interventions and reported according to the PRISMA statement [30] (www. prisma-statement.org). The protocol was registered on the PROSPERO (http://www.crd. york.ac.uk/PROSPERO, ID: CRD42018100562).

\section{Data sources and search strategy}

The current issue of the Cochrane Central Register of Controlled Trials (CENTRAL; 2017, Issue 9), PubMed (1946 to October 30th, 2018), EMBASE (1974 to October 30th, 2018), and Web of Science (1900 to October 30th, 2018) were searched. Study authors were mailed for any useful information. The reference lists of all eligible trials and reviews were screened for additional citations. No language restriction was imposed. The search strategies of the four electronic databases were provided in Table 1.

\section{Eligibility criteria}

RCTs, quasi-RCTs, and observational (prospective or retrospective) studies comparing VL and DL and reporting the adverse events of tracheal intubations in the ED and ICU patients were included. Conference abstracts with available data were also included. Studies in which VL or DL was used as a rescue device were excluded. Pre-hospital study, manikin study, cadaver study, simulated study, or case reports were also excluded. Participants were in-hospital non-surgical patients needing urgent tracheal intubations in the ED and ICU. Patients with a suspected laryngeal trauma or an extensive maxillofacial injury requiring an immediate surgical airway, supraglottic airway, or awake fiberoptic intubation were excluded. Patients in the intervention group used a VL. When the C-MAC or McGrath MAC laryngoscope was used for DL by inexperienced operator, the attempt was considered a VL, regardless of whether the operator looked at the monitor. In this case, the supervising attending physician was able to view the video monitor and assist with the tracheal intubation [5]. For patients in the control group, a DL was used. Optimizing maneuvers such as the external laryngeal pressure, the use of intubation stylet or introducer, could be initiated at the discretion of the operator.

\section{Study selection and data extraction}

The titles and abstracts were independently screened by two study authors (J.J.; N.K.). After retrieving the fulltexts or conference abstract of any potentially relevant studies, their eligibilities were determined. Any disagreements between the two review authors were resolved by discussion with other authors until a consensus was obtained. A PRISMA flow diagram was completed to record the selection process in detail [31].

Data was independently extracted by two review authors (J.).; N.K.). All the outcomes were dichotomous variables, the number of events occurred and the sample sizes were extracted. Any disagreement on data 
Table 1 Search strategy for four databases

\begin{tabular}{|c|c|}
\hline Database & Search Strategy \\
\hline PubMed & 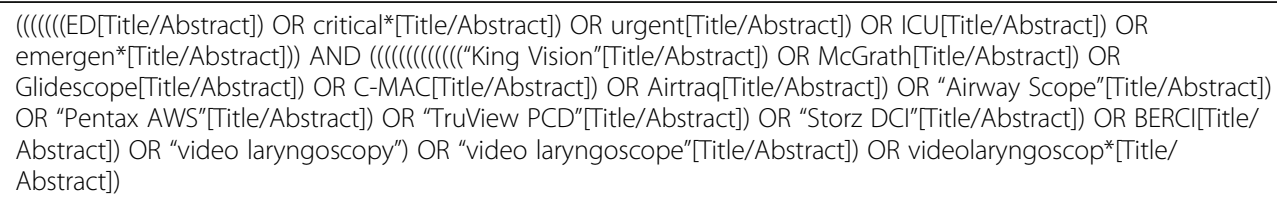 \\
\hline Embase & $\begin{array}{l}\text { ('videolaryngoscopy':ab,ti OR 'videolaryngoscope'ab,ti OR 'video laryngoscopy':ab,ti OR 'video laryngoscope':ab,ti } \\
\text { OR 'king vision':ab,ti OR glidescope:ab,ti OR mcgrath:ab,ti OR 'c mac':ab,ti OR airtraq:ab,ti OR 'airway scope':ab,ti } \\
\text { OR 'pentax aws':ab,ti OR truview:ab,ti OR 'storz dci':ab,ti OR berci:ab,ti) AND (emergen*:ab,ti,kw OR critical*:ab,kw,ti } \\
\text { OR icu:ab,kw,ti OR ed.:ab,ti,kw) AND ('case report'/de OR 'clinical article'/de OR 'clinical trial'/de OR 'comparative } \\
\text { study'/de OR 'controlled clinical trial'/de OR 'controlled study'/de OR 'crossover procedure'/de OR 'human'/de OR } \\
\text { 'human experiment'/de OR 'intermethod comparison'/de OR 'major clinical study'/de OR 'meta analysis'/de OR } \\
\text { 'multicenter study'/de OR 'observational study'/de OR 'prospective study'/de OR 'randomized controlled trial'/de } \\
\text { OR 'randomized controlled trial (topic)'/de OR 'retrospective study'/de OR 'total quality management'/de) }\end{array}$ \\
\hline $\begin{array}{l}\text { Cochrane Central Register of } \\
\text { Controlled Trials }\end{array}$ & $\begin{array}{l}\text { 'videolaryngoscopy or videolaryngoscope or videolaryngoscopic or videolaryngoscopes or "video laryngoscopy" } \\
\text { or "video laryngoscope" or "video laryngoscopic" or "video laryngoscopes" or "King Vision" or McGrath or } \\
\text { Glidescope or C-MAC OR Airtraq or "Airway Scope" or "Pentax AWS" or "TruView PCD" or "Storz DCI" or BERCI in } \\
\text { Title, Abstract, Keywords and emergent or critical or ICU or urgent in Title, Abstract, Keywords' }\end{array}$ \\
\hline Web of Science & $\begin{array}{l}\mathrm{TI}=\text { (videolaryngoscop* OR "video laryngoscop*" OR "King Vision" OR Glidescope OR McGrath OR C-MAC OR Air- } \\
\text { traq OR "Airway Scope" OR "Pentax AWS" OR "TruView PCD" OR "Storz DCI" OR "BERCI" OR "AP Advance") AND } \\
\text { TS = (urgent or ICU or ED or critical* or emergen*) } \\
\text { Index = SCI-EXPANDED, SSCI, A\&HCL, ESCI Timespan = All years }\end{array}$ \\
\hline
\end{tabular}

extraction was resolved by discussion with a third author (F.S.X.) until a consensus was reached.

\section{Primary and secondary outcomes}

The esophageal intubation (EI) is rare, but is one of mostly severe adverse events associated with tracheal intubation in the ICU and ED patients [3]. Thus, the rate of EI was used as primary outcome. If the rates of EI at the first-attempt and at any attempt were given, the rate of EI at the first-attempt was only used. The secondary outcomes were incidences of hypoxemia $\left(\mathrm{SpO}_{2}<90 \%\right)$ and severe hypoxemia $\left(\mathrm{SpO}_{2}<80 \%\right)$ during the intubation procedure, incidence of aspiration (any witnessed aspiration of gastric contents during the intubation attempt or defined by the original author), incidence of new-onset cardiac arrest (during or immediately after intubation), short-term (within $24 \mathrm{~h}$ ) and long-term (28 d or in-hospital) all-causes mortality.

\section{Risk of bias assessment}

The risk of bias for each eligible study was independently assessed by two review authors (J.J. and N.K.). For RCTs (including quasi-RCT), the Cochrane Collaboration's tool was used to assess the risk of bias [32]. Each of the seven domains, such as random sequence generation, allocation concealment, blinding of participants and personnels, blinding of outcome assessment, incomplete outcome data, selective reporting, and other biases, was judged as either low, high, or unclear. If all domains were assigned to the "low risk" of bias category, the study was classified as "low risk"; if one or more domains were assigned to the "unclear risk" of bias category, the study was classified as "unclear risk"; if one or more domains were assigned to the high risk of bias category, the study was classified as "high risk" [32]. For observational studies, the ACROBAT-NRSi Cochrane Risk of Bias Tool was used [33]. Each of the seven domains, such as confounding, selection of participants, classification of interventions, deviations from intended interventions, missing data, measurement outcomes, and selection of the reported outcomes, was judged as either low, moderate, severe, or unclear. The possible confounding domains are "experience of operators, difficult airways, number of patients with CPR, and the use of neuromuscular blockades". No co-interventions were considered. An overall judgement of the risk of bias for each study was reached as low, moderate, serious, critical or no information on the risk of bias. Reporting bias was also assessed by using funnel plot if the result of primary outcome was from at least 10 trials [34].

The criteria of the Grading of Recommendations Assessment, Development and Evaluation (GRADE) system (study limitations, consistency of effect, imprecision, indirectness, and publication bias) were applied to assess the quality of evidence associated with all outcomes $[35,36]$. Then a "Grade evidence profile" table was developed by using the GRADE software (www.guide linedevelopment.org) to rate these outcomes as high, moderate, low, or very low quality. Since different types of studies were involved in this review, the quality of the evidence was assessed for the RCTs (including quasi-RCT) and non-RCTs, respectively. The quality of evidence was downgraded by one or two levels when serious or very serious deficiencies were considered in these criteria. 
Trial sequential analysis (TSA) was performed for all adverse events from RCTs $[37,38]$. The information size required was calculated to provide an estimate of how many more patients would be required to make a reliable conclusion. A conventional calculation for sample size estimation, with conventional values for $\alpha$ and $\beta$ error (0.05 and 0.20), low bias-based relative risk reduction, the incidence in control arm, and a model variance-based heterogeneity correction was used.

\section{Statistical analysis}

The study authors of the original report were contacted for important missing statistics. For the participants missing due to dropout, if "missing at random", analysis was performed based on the available data; if not, an available case analysis was performed and the potential bias was explained in discussion section. If a study did not mention withdrawals, no drop-out was assumed.

Both relative risk (RR) and 95\% confidence interval (CI) were used for dichotomous data. $P<0.05$ was considered statistically significant. Review Manager was applied to perform the pooled analyses for the outcomes from more than one study. A Chi-squared test with the $I^{2}$ statistic (with statistical significance set at the level of two-tailed 0.10) was used to describe the percentage of the total variance across studies from heterogeneity rather than from chance. If $I^{2}$ is $<40 \%$, namely there was no statistical heterogeneity among studies, and a fixedeffect model was used; otherwise, a random-effect model was used. For the results that could not be analyzed via meta-analysis, only a qualitative systematic review was planned instead of excluding that study.

Clinical and methodological heterogeneities were considered before performing pooled analysis. In the presence of a statistical heterogeneity or an indication of clinical heterogeneity, subgroup analysis was carried out for all outcomes according to the following possible heterogeneous factors: the type of studies, RCTs or nonRCTs; whether a specialized CPR study; and operators' expertise: experienced (certificated anesthesiologist, physicians of emergency medical services with no less than three years of clinical experience, physicians performed 50 successful tracheal intubations, or according to the judgment of authors) or inexperienced. If both experienced and inexperienced operators were involved in one study, the sub-grouping of the expertise was determined by the majority part.

\section{Results}

\section{Characteristic of included studies}

Using search strategy, a total of 1729 papers were identified. Of them, 1661 were excluded during title and abstract screening due to duplicates and being irrelevant to our research question. Sixty-eight studies were selected for full-text assessment using inclusion and exclusion criteria. Forty-five studies were further removed because of no available data $(n=27)$, overlapping data sets $(n=$ $9)$, or irrelevant $(\mathrm{n}=9)$. Finally, 23 studies $(n=13,117)$ including one conference abstract were eventually included in the review for data extraction. Authors from three studies $[3,6,14]$ were contacted for detailed information on important data, only one of them replied [3]. The flow chart of included and excluded studies is shown in Fig. 1.

The characteristics of included studies are listed in Table 2. Of the 23 included studies, 9 were carried out in the ICU $[4,5,7,9,14,16,17,19,20], 11$ in the ED, one in both the ICU and wards [6], one in general wards [8], and the other in out-of-operating room location [39]; 4 studies enrolled only patients with cardiac arrest $[8,10,11,18]$ and 4 excluded patients with cardiac arrest $[16,19,21,22] ; 6$ studies used a VL with a standard blade (C-MAC) [9, 12, 13, 15, 21, 40], 12 used a VL with an angled blade (GlideScope, McGrath, UEscope) [4, 6, $7,11,14,16,18-20,22,39,41]$, and 5 combined several types of VLs (Angled: GlideScope and McGrath; Standard: C-MAC; Channeled: AirwayScope, or KingVision) [3, 5, 8, 10, 17]; tracheal intubation was performed mostly by experienced operators in 7 studies $[9,13,14,18,21,22,39]$, the meeting abstract did not mention the expertise of the operators; Rapid sequence induction (RSI) with sedatives and neuromuscular blockades was chosen as needed in most included studies except for the CPR patients or the studies performed in the CPR patients, 2 studies did not mention the anesthesia induction method $[39,41]$.

\section{Risk of bias assessment for included studies}

Detailed description regarding the risk of bias of the included studies is shown in Table 3. Of the 23 included studies, 9 were RCTs [13-19, 21, 22], one was quasi-RCT [20], and the others were observational studies. The overall risk of bias for most of the included RCTs was rated as low, but the overall risk of bias for the observational studies was rated as moderate or serious mainly due to confounding domains. The funnel plot obtained from primary outcome with its visually symmetrical distribution qualitatively indicated a low risk of publication bias (Additional file 1: Fig. S1). The GRADE system showed that the quality of evidence from most RCTs was high or moderate, whereas the quality of evidence from most non-RCTs was very low. The quality of evidence was downgraded manly due to inconsistency from moderate or high level of heterogeneity and imprecision from few participants and few events. The results regarding the quality of evidence for different adverse events were listed in Additional file 2: Table S1. 


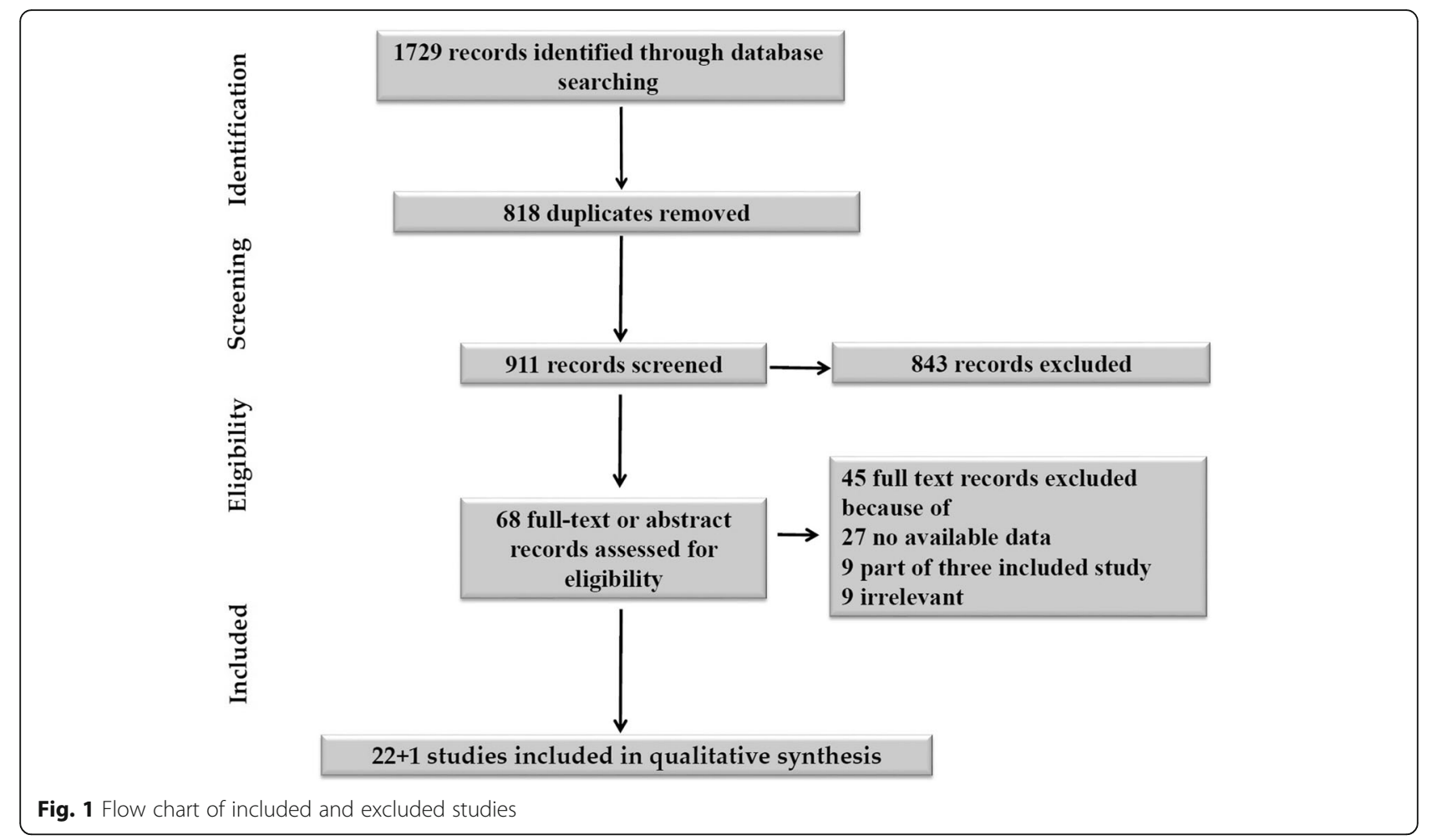

\section{Rate of El}

Eighteen studies reported the rate of EI [3-7, 9-12, 14, 15, 17-21, 39, 41]; among them, 2 studies reported the rate of EI based on the number of intubations rather than the number of patients $[4,12]$, one study reported based on the attempts instead of the number of patients [3]. We emailed the original authors for the data based on patients and the initial intubation devices, but the data were not available. After discussion with other authors in our study, we decided to use the current data and do a sensitive analysis by excluding the data from these 3 studies [3, 4, 12].

Pooled analysis showed a significant difference in the rate of EI between VL and DL (RR, 0.24; 95\% CI, 0.18-0.32; $n=$ 11,187; $P<0.01$; high-quality evidence for RCTs and very low-quality evidence for observational studies). There was no significant heterogeneity among studies $\left(P=0.05 ; I^{2}=\right.$ 39\%) (Additional file 1: Fig. S2). Sensitive analysis by excluding the data from 3 studies mentioned above did not change the pooled result. Subgroup analyses based on the type of studies, whether a CPR study, or operators' expertise showed a lower rate of EI by using VL compared with DL in all subgroups $(P<0.01)$ except for experienced operators (5 studies; RR, 0.44; 95\% CI, 0.17-1.15; $n=1100 ; P=$ 0.09; Fig. 2, Additional file 1: Fig. S3-S4).

\section{Other adverse events}

Results of adverse events including hypoxemia, severe hypoxemia, aspiration, new-onset cardiac arrest, 24h- mortality, and $28 \mathrm{~d}$-mortality are summarized in Table 4 and Additional file 1: Fig. S5-S19.

Three studies reported the incidence of hypoxemia $[9,14$, 19]. One study, which reported the rate of decline in oxygen saturation greater than 10\% from baseline [5], was also included in the pooled analysis. All of them are non-CPR studies. Eight studies reported the incidence of severe hypoxemia $[4,6,7,9,14,17,19,20]$, all of them are non-CPR studies. Thirteen studies reported the incidence of aspiration $[4,5,7,9,13,14,17,19-22,39,40]$. Seven studies reported the incidence of new-onset cardiac arrest $[4,5,12$, $14,17,19,20]$. Six studies reported short-term mortality within $24 \mathrm{~h}[4,7,8,14,19,20]$, and 7 studies reported longterm mortality (28 d or in-hospital) [4, 8, 13, 16, 17, 19, 22]; among them, one reported the data based on the number of intubations rather than the number of participants [4]. The available data was used because both the number of intubations and that of participants were quite similar. Pooled analyses for all these outcomes showed no significant differences between VL and DL $(P>0.05)$. For these adverse events, however, there was no significant heterogeneity among studies $\left(I^{2}<40 \%\right)$. Subgroup analyses for all these adverse events based on the type of studies, whether a CPR study, or operators' expertise showed no significant difference between VL and DL in all subgroups $(P>0.05)$ except for the incidence of hypoxemia when intubated by inexperienced operators $(P=0.03)$.

The incidences of hypoxemia and severe hypoxemia in both groups were almost 2-3 times higher in the non- 


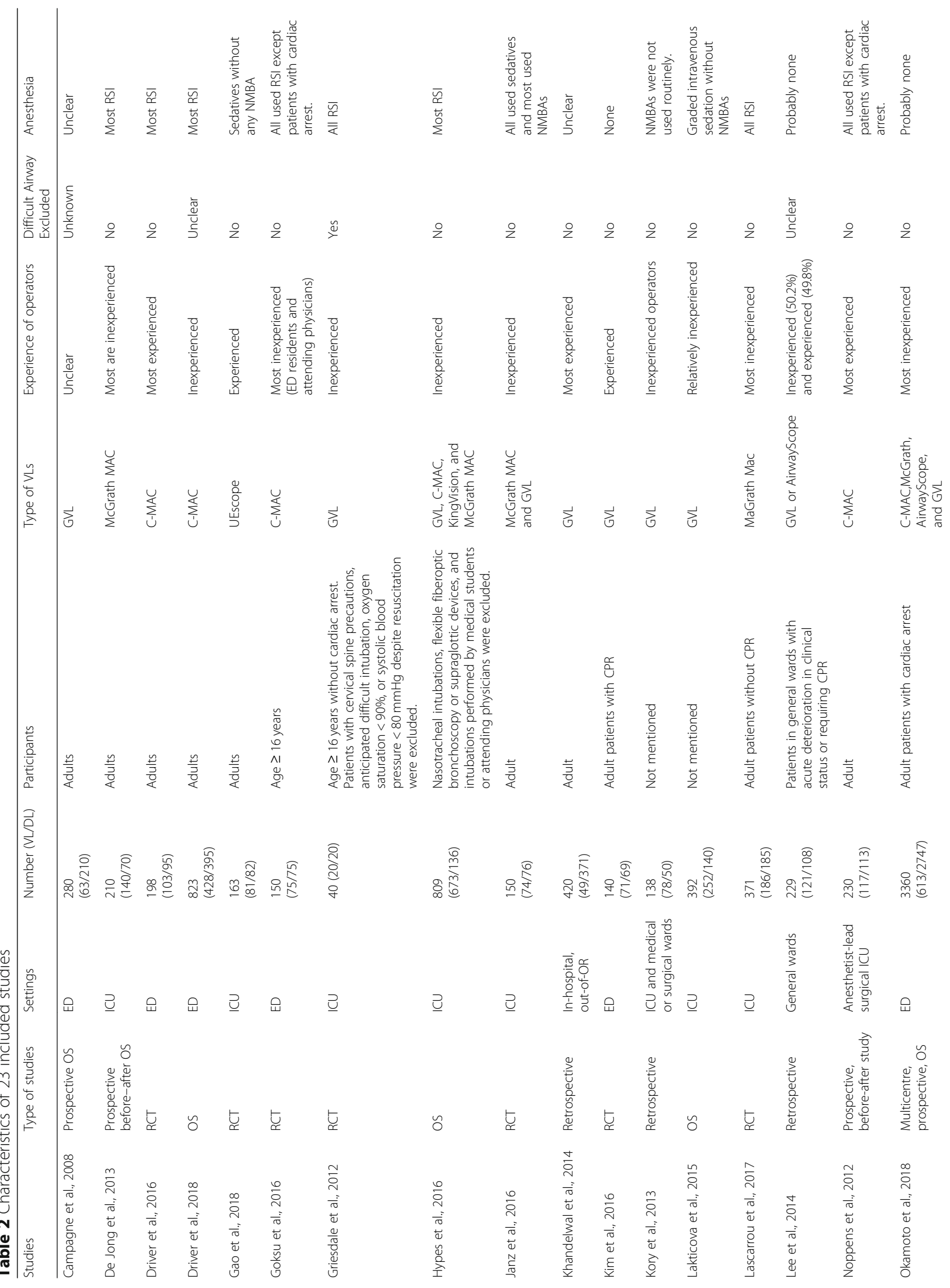




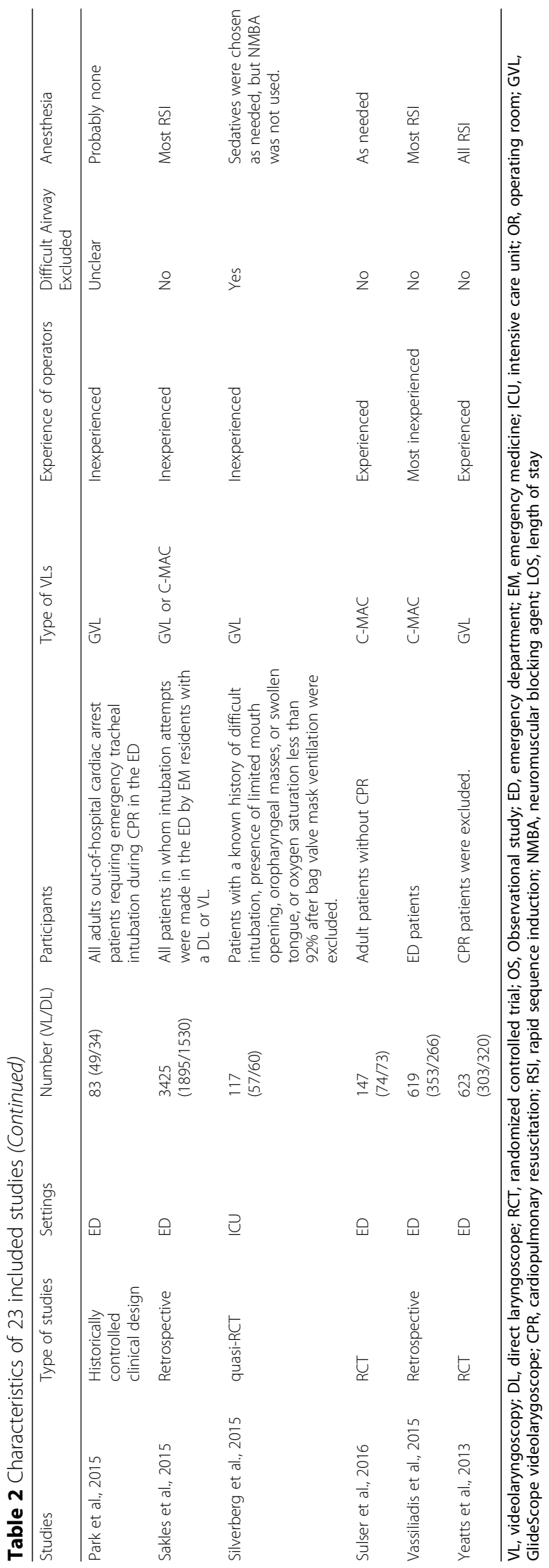


Table 3 Risk of bias assessment of 23 included RCTs and non-RCTs

\begin{tabular}{|c|c|c|c|c|c|c|c|c|c|}
\hline \multirow[t]{11}{*}{ RCTs } & Study Authors & $\begin{array}{l}\text { Random } \\
\text { sequence } \\
\text { generation }\end{array}$ & $\begin{array}{l}\text { Allocation } \\
\text { concealment }\end{array}$ & $\begin{array}{l}\text { Blinding of } \\
\text { participants } \\
\text { and personnel }\end{array}$ & $\begin{array}{l}\text { Blinding of } \\
\text { outcome } \\
\text { assessment }^{a}\end{array}$ & $\begin{array}{l}\text { Incomplete } \\
\text { outcome data }\end{array}$ & $\begin{array}{l}\text { Selective } \\
\text { reporting }\end{array}$ & Other bias & Overall \\
\hline & Driver et al., 2016 & Low & Low & Low & Low & Low & Low & Low & Low \\
\hline & Gao et al., 2018 & Unclear & Unclear & Low & Low & Low & Low & Low & Unclear \\
\hline & Goksu et al., 2016 & Low & Low & Low & Low & Low & Low & Low & Low \\
\hline & Griesdale et al., 2012 & Low & Low & Low & Low & Low & Low & Low & Low \\
\hline & Janz et al., 2016 & Low & Low & Low & Low & Low & Low & Low & Low \\
\hline & Kim et al., 2016 & Low & Low $^{b}$ & low & low & Low & low & low & Low \\
\hline & Lascarrou et al., 2017 & Low & Low & Low & Low & Low & Low & Low & Low \\
\hline & Silverberg et al., 2015 & $\mathrm{High}^{c}$ & Unclear & Low & Low & Low & Low & Low & High \\
\hline & Susler et al., 2016 & Low & Low & Low & Low & Low & Low & Low & Low \\
\hline & Yeatts et al., 2013 & Low & Low & Low & Low & $\operatorname{High}^{d}$ & Low & Low & High \\
\hline \multirow[t]{14}{*}{$\begin{array}{l}\text { non- } \\
\text { RCTs }\end{array}$} & Study Authors & Confounding & $\begin{array}{l}\text { Selection of } \\
\text { participants } \\
\text { into study }\end{array}$ & $\begin{array}{l}\text { Classification of } \\
\text { interventions }\end{array}$ & $\begin{array}{l}\text { Deviations from } \\
\text { intended } \\
\text { interventions }\end{array}$ & Missing data & $\begin{array}{l}\text { Measurement } \\
\text { of outcomes }\end{array}$ & $\begin{array}{l}\text { Selection } \\
\text { of reported } \\
\text { results }\end{array}$ & Overall \\
\hline & Campagne et al., 2008 & Unclear & Unclear & Unclear & Unclear & Unclear & Unclear & Unclear & Unclear \\
\hline & De Jong et al., 2013 & Serious $^{\mathrm{e}}$ & Moderate & Moderate & Moderate & Moderate & Serious $^{f}$ & Low & Serious \\
\hline & Driver et al., 2018 & Moderate & Moderate & Moderate & Moderate & Moderate & Low & Low & Moderate \\
\hline & Hypes et al., 2016 & Moderate & Moderate & Moderate & Moderate & Moderate & Moderate & Low & Moderate \\
\hline & Khandelwal et al., 2014 & Moderate & Moderate & Moderate & Moderate & Moderate & Moderate & Low & Moderate \\
\hline & Kory et al., 2013 & Moderate & Moderate & Moderate & Moderate & Moderate & Serious $^{g}$ & Low & Serious \\
\hline & Lakticova et al., 2015 & Moderate & Moderate & Moderate & Moderate & Moderate & Moderate & Low & Moderate \\
\hline & Lee et al., 2014 & Serious ${ }^{\mathrm{e}}$ & Moderate & Moderate & Moderate & Moderate & Moderate & Low & Serious \\
\hline & Noppens et al., 2012 & Serious $^{\mathrm{e}}$ & Moderate & Moderate & Moderate & Moderate & Moderate & Low & Serious \\
\hline & Okamoto et al., 2018 & Serious eh & Moderate & Moderate & moderate & Moderate & Moderate & Low & Serious \\
\hline & Park et al., 2015 & Moderate & Moderate & Moderate & Moderate & Moderate & Moderate & Low & Moderate \\
\hline & Sakles et al., 2015 & Moderate & Moderate & Moderate & Moderate & Moderate & Serious & Low & Serious \\
\hline & Vassiliadis et al., 2015 & Moderate & Moderate & Moderate & Moderate & Moderate & Serious $^{f}$ & Low & Serious \\
\hline
\end{tabular}

${ }^{a}$ Although all studies did not use blinded method, authors judged that the outcome would not be likely to be influenced as patients were unaware of their grouping and it was impossible for operators to be unaware of the patients' grouping during intubation process. Moreover, although subjective judgments may bias the results in the absence of blinding, most of our important endpoints are robust; ${ }^{\mathbf{b}}$ Intubation was required so emergently that a randomization envelope could not be obtained; ${ }^{\mathrm{C}} \mathrm{An}$ even/odd numbered randomization strategy was used; ${ }^{\mathrm{d}}$ There was no reason for missing data provided in this study.

${ }^{\mathrm{e}}$ The skill of operators was significantly different between groups; ${ }^{\mathrm{f}}$ The analysis was based on the number of intubations rather than the number of patients; ${ }^{9} \mathrm{The}$

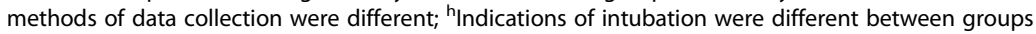

RCTs than in the RCTs (21-30\% vs. $11-12 \%$ for hypoxemia; $10-12 \%$ vs. $6-6.7 \%$ for severe hypoxemia, $P>$ 0.05). The incidence of aspiration in both groups was higher in the non-RCTs than in the RCTs $(3-4.5 \%$ vs. $2.5-2.7 \%, P>0.05)$.

\section{Trial sequential analysis}

The TSA of a diversity-adjusted required information size for the rate of EI was 668 patients. The cumulative $\mathrm{z}$-curve crossed the boundary of required information size and TSA monitoring boundary for favoring VL. Thus, this pooled analysis from RCTs is conclusive, namely, the use of VL reduces the rate of EI. For incidences of aspiration and new-onset cardiac arrest, and short-term mortality, the cumulative z-curve did not cross the boundary of required information size and TSA monitoring boundary. Thus, the pooled analyses from RCTs for these adverse outcomes are inconclusive. For incidence of hypoxemia and long-term mortality, boundary TSA is ignored due to too little information size. Thus, the pooled analyses from RCTs for these adverse outcomes are also inconclusive (Additional file 1: Fig. S20A-G and Additional file 2: Table S2).

In summary, pooled analysis showed that the use of VL reduced the rate of EI, especially for inexperienced operators. As to the other adverse outcomes, however, no significant differences were identified, except for the incidence of hypoxemia when intubated by inexperienced operators. 


\begin{tabular}{|c|c|c|c|c|c|c|c|c|c|c|}
\hline Study or Subgroup & \multicolumn{2}{|l|}{ VL } & \multicolumn{2}{|l|}{$\mathrm{DL}$} & Weight & \multicolumn{2}{|l|}{ Risk Ratio } & \multicolumn{2}{|c|}{$\begin{array}{c}\text { Risk Ratio } \\
\text { M-H, Fixed, 95\% Cl }\end{array}$} & \\
\hline Campagne 2008 & 0 & 63 & 4 & 217 & $0.8 \%$ & $0.38[0.02,6.94]$ & & & - & \\
\hline De Jong 2013 & 4 & 70 & 8 & 140 & $2.0 \%$ & $1.00[0.31,3.21]$ & & & $\square$ & \\
\hline Gao 2018 & 3 & 81 & 6 & 82 & $2.3 \%$ & $0.51[0.13,1.96]$ & & & - & \\
\hline Goksu 2016 & 0 & 75 & 7 & 75 & $2.9 \%$ & $0.07[0.00,1.15]$ & & & & \\
\hline Hypes 2016 & 13 & 673 & 7 & 135 & $4.5 \%$ & $0.37[0.15,0.92]$ & & & & \\
\hline Janz 2016 & 1 & 74 & 4 & 76 & $1.5 \%$ & $0.26[0.03,2.24]$ & & & - & \\
\hline Khandelwal 2014 & 1 & 49 & 4 & 371 & $0.4 \%$ & $1.89[0.22,16.59]$ & & & & \\
\hline Kim 2016 & 0 & 71 & 3 & 69 & $1.4 \%$ & $0.14[0.01,2.64]$ & & & - & \\
\hline Kory 2013 & 0 & 78 & 7 & 50 & $3.5 \%$ & $0.04[0.00,0.74]$ & & & & \\
\hline Lakticova 2015 & 1 & 252 & 27 & 140 & $13.3 \%$ & $0.02[0.00,0.15]$ & & & & \\
\hline Lascarrou 2017 & 3 & 184 & 6 & 181 & $2.3 \%$ & $0.49[0.12,1.94]$ & & & - & \\
\hline Noppens 2012 & 0 & 117 & 2 & 113 & $1.0 \%$ & $0.19[0.01,3.98]$ & & & & \\
\hline Okamoto 2018 & 10 & 613 & 144 & 2747 & $20.2 \%$ & $0.31[0.16,0.59]$ & & $\rightarrow-$ & & \\
\hline Park 2015 & 0 & 49 & 6 & 34 & $2.9 \%$ & $0.05[0.00,0.93]$ & & & & \\
\hline Sakles 2015 & 18 & 1895 & 78 & 1530 & $33.2 \%$ & $0.19[0.11,0.31]$ & & $\rightarrow-$ & & \\
\hline Silwerberg 2015 & 0 & 57 & 4 & 60 & $1.7 \%$ & $0.12[0.01,2.12]$ & & & - & \\
\hline Sulser 2016 & 0 & 74 & 0 & 73 & & Not estimable & & & & \\
\hline Vassiliadis 2015 & 9 & 353 & 14 & 266 & $6.1 \%$ & $0.48[0.21,1.10]$ & & $\rightarrow$ & & \\
\hline Total $(95 \% \mathrm{Cl})$ & & 4828 & & 6359 & $100.0 \%$ & $0.24[0.18,0.32]$ & & $\bullet$ & & \\
\hline Total ewents & 63 & & 331 & & & & & & & \\
\hline $\begin{array}{l}\text { Heterogeneity: } \text { Chi }^{2}= \\
\text { Test for overall effect }\end{array}$ & $\begin{array}{l}26.27, \mathrm{df}= \\
\mathrm{Z}=10.27\end{array}$ & $\begin{array}{l}=16(P \\
(P \leq 0 .\end{array}$ & $\begin{array}{l}=0.05) ; \\
00001)\end{array}$ & $F^{2}=399$ & & & 0.001 & $\begin{array}{c}0.1 \\
\text { Favours [VL] }\end{array}$ & $\begin{array}{c}10 \\
\text { Favours [DL] }\end{array}$ & 1000 \\
\hline
\end{tabular}

\section{Discussion}

This systematic review and meta-analysis is focused on adverse events of tracheal intubation using VL compared with DL in the ED and ICU patients by including both RCTs and observational studies. Pooled analysis showed that the use of VL reduced the rate of EI; as to the other adverse outcomes, however, no significant differences were identified.

The rate of EI was chosen as the primary outcome in this analysis, as even a single episode of recognized EI is significantly associated with desaturation, increased risk of aspiration and cardiac arrest. It has been shown that patients with EI have higher incidences of aspiration (6.1 times), dysrhythmia (6.4 times), hypotension (3.1 times), and hypoxemia [3]. In our analysis, however, a significant lower rate of EI by using VL did not result in any significant difference for other adverse events. This is probably due to small sample size, leading these results inconclusive, as the TSA has proved. Even though, a lower trend for the incidences of hypoxemia and aspiration with VL can still be identified. Inexperienced operators benefited more from using VL, with significant lower incidences of EI and hypoxemia. For inexperienced operators who have not performed the tracheal intubation with VL and DL, visualization of the airway on VL screen can allow their supervisors to directly assist them in completing tracheal intubation themselves, thus improving the success rate [42]. In contrast, experienced operators with extensive training and experience on the tracheal intubation using DL might overshadow the benefits of VL, especially when patients have a normal airway or there are some VL-related difficult scenarios like secretions or blood in the airway or certain VL design-related deficiencies which may bate their benefits [19, 22, 43, 44].

Different from above non-fatal adverse outcomes, an increased trend was otherwise shown for incidence of new-onset cardiac arrest and short-term mortality by using VL. However, it should be noted that among the studies reporting the results of new-onset cardiac arrest and short-term mortality, only one was the study in which emergency tracheal intubation was performed by experienced operators [14]. The longer duration of intubation with VL by inexperienced operators may result in an increased risk of severe life-threatening adverse outcomes [19]. In addition, the pooled result of the short-term mortality was mainly from a CPR study [8]. Although the participants were randomized, the baseline clinical characteristics for both groups was not comparable, with more ischemic heart diseases in the VL group, leading the patients in this group to be at a higher risk of severe adverse outcomes. It has been reported that the use of a VL can reduce the chest compression interruptions for both experienced and inexperienced operators $[11,18]$. However, visualization of VL can be unfavorably compromised by increased amount of 
Table 4 Results of meta-analysis for all adverse events between direct laryngoscope and video laryngoscope

\begin{tabular}{|c|c|c|c|c|c|c|}
\hline Outcomes & Studies, N & Participants, N & Heterogeneity & $\begin{array}{l}\text { Heterogeneity Statistical } \\
\text { method }\end{array}$ & Effect Estimate & $P$ values \\
\hline Rate of El & 18 & 11,187 & $P=0.05 ; P^{2}=39 \%$ & RR (M-H, Fixed, 95\% Cl) & $0.24[0.18,0.32]$ & $P<0.01$ \\
\hline Rate of El (RCT) & 7 & 1232 & $P=0.70 ; P^{2}=0 \%$ & RR (M-H, Fixed, 95\% Cl) & $0.27[0.13,0.57]$ & $P<0.01$ \\
\hline Rate of El (non-RCT) & 11 & 9955 & $P=0.01 ; P^{2}=57 \%$ & RR (M-H, Fixed, 95\% Cl) & $0.24[0.18,0.32]$ & $P<0.01$ \\
\hline Rate of El (CPR) & 4 & 3723 & $P=0.44 ; P^{2}=0 \%$ & RR (M-H, Fixed, 95\% Cl) & $0.27[0.15,0.49]$ & $P<0.01$ \\
\hline Rate of El (non-CPR) & 15 & 7464 & $P=0.03 ; P^{2}=46 \%$ & RR (M-H, Fixed, 95\% Cl) & $0.23[0.17,0.31]$ & $P<0.01$ \\
\hline Rate of El (experienced) & 5 & 1100 & $P=0.45 ; P^{2}=0 \%$ & RR (M-H, Fixed, 95\% Cl) & $0.44[0.17,1.15]$ & $P=0.09$ \\
\hline Rate of El (inexperienced) & 12 & 9807 & $P=0.02 ; P^{2}=50 \%$ & RR (M-H, Fixed, 95\% Cl) & $0.23[0.17,0.31]$ & $P<0.01$ \\
\hline Rate of El (unknown expertise) & 1 & 280 & Not applicable & RR (M-H, Fixed, 95\% Cl) & $0.38[0.02,6.94]$ & $P=0.51$ \\
\hline Incidence of hypoxemia & 4 & 1548 & $P=0.35 ; P^{2}=8 \%$ & RR (M-H, Fixed, 95\% Cl) & $0.85[0.69,1.05]$ & $P=0.14$ \\
\hline Incidence of hypoxemia (RCT) & 2 & 510 & $P=0.34 ; P^{2}=0 \%$ & RR (M-H, Fixed, 95\% Cl) & $0.91[0.56,1.47]$ & $P=0.70$ \\
\hline Incidence of hypoxemia (non-RCT) & 2 & 1038 & $P=0.13 ; P^{2}=56 \%$ & RR (M-H, Fixed, 95\% Cl) & $0.83[0.66,1.05]$ & $P=0.13$ \\
\hline Incidence of hypoxemia (experienced) & 2 & 393 & $P=0.70 ; I^{2}=0 \%$ & RR (M-H, Fixed, 95\% Cl) & $1.05[0.77,1.43]$ & $P=0.76$ \\
\hline Incidence of hypoxemia (inexperienced) & 2 & 1155 & $P=0.89 ; l^{2}=0 \%$ & RR (M-H, Fixed, 95\% Cl) & $0.71[0.53,0.96]$ & $P=0.03$ \\
\hline Incidence of severe hypoxemia & 8 & 1739 & $P=0.26 ; P^{2}=22 \%$ & RR (M-H, Fixed, 95\% Cl) & $1.13[0.83,1.52]$ & $P=0.44$ \\
\hline Incidence of severe hypoxemia (RCT) & 4 & 787 & $P=0.18 ; P^{2}=39 \%$ & RR (M-H, Fixed, 95\% Cl) & $1.11[0.66,1.87]$ & $P=0.39$ \\
\hline Incidence of severe hypoxemia (non-RCT) & 4 & 952 & $P=0.26 ; P^{2}=26 \%$ & RR (M-H, Fixed, 95\% Cl) & $1.13[0.78,1.64]$ & $P=0.52$ \\
\hline Incidence of severe hypoxemia (experienced) & 2 & 393 & $P=0.46 ; P^{2}=0 \%$ & RR (M-H, Fixed, 95\% Cl) & $1.16[0.62,2.16]$ & $P=0.65$ \\
\hline Incidence of severe hypoxemia (inexperienced) & 6 & 1346 & $P=0.14 ; I^{2}=40 \%$ & RR (M-H, Fixed, 95\% Cl) & $1.12[0.79,1.58]$ & $P=0.53$ \\
\hline Incidence of aspiration & 13 & 4634 & $P=0.98 ; P^{2}=0 \%$ & RR (M-H, Fixed, 95\% Cl) & $0.83[0.60,1.16]$ & $P=0.28$ \\
\hline Incidence of aspiration (RCT) & 7 & 1751 & $P=0.79 ; P^{2}=0 \%$ & RR (M-H, Fixed, 95\% Cl) & $0.90[0.52,1.58]$ & $P=0.72$ \\
\hline Incidence of aspiration (non-RCT) & 6 & 2883 & $P=0.92 ; P^{2}=0 \%$ & RR (M-H, Fixed, 95\% Cl) & $0.80[0.53,1.21]$ & $P=0.28$ \\
\hline Incidence of aspiration (CPR) & 1 & 140 & Not applicable & RR (M-H, Fixed, 95\% Cl) & $5.58[0.25,126.46]$ & $P=0.28$ \\
\hline Incidence of aspiration (non-CPR) & 13 & 4494 & $P=0.97 ; P^{2}=0 \%$ & RR (M-H, Fixed, 95\% Cl) & $0.83[0.59,1.16]$ & $P=0.27$ \\
\hline Incidence of aspiration (experienced) & 6 & 1769 & $P=0.88 ; P^{2}=0 \%$ & RR (M-H, Fixed, 95\% Cl) & $0.65[0.32,1.32]$ & $P=0.24$ \\
\hline Incidence of aspiration (inexperienced) & 7 & 2865 & $P=0.92 ; P^{2}=0 \%$ & RR (M-H, Fixed, 95\% Cl) & $0.90[0.61,1.31]$ & $P=0.57$ \\
\hline Incidence of new-onset CA & 7 & 2433 & $P=0.20 ; I^{2}=31 \%$ & RR (M-H, Fixed, 95\% Cl) & $1.52[0.63,3.66]$ & $P=0.35$ \\
\hline Incidence of new-onset CA (RCT) & 4 & 795 & $P=0.56 ; P^{2}=0 \%$ & RR (M-H, Fixed, 95\% Cl) & $3.51[0.73,16.92]$ & $P=0.12$ \\
\hline Incidence of new-onset CA (non-RCT) & 3 & 1638 & $P=0.09 ; I^{2}=58 \%$ & RR (M-H, Fixed, 95\% Cl) & $0.86[0.27,2.70]$ & $P=0.79$ \\
\hline Incidence of new-onset CA (experienced) & 1 & 163 & Not applicable & RR (M-H, Fixed, 95\% Cl) & $3.04[0.13,73.46]$ & $P=0.49$ \\
\hline Incidence of new-onset CA (inexperienced) & 6 & 2270 & $P=0.14 ; I^{2}=43 \%$ & RR (M-H, Fixed, 95\% Cl) & $1.42[0.57,3.56]$ & $P=0.45$ \\
\hline 24 h-mortality & 6 & 1477 & $P=0.82 ; P^{2}=0 \%$ & RR (M-H, Fixed, 95\% Cl) & $1.29[0.98,1.69]$ & $P=0.07$ \\
\hline 24 h-mortality $(\mathrm{RCT})$ & 3 & 646 & $P=1.00 ; P^{2}=0 \%$ & RR (M-H, Fixed, 95\% Cl) & $3.06[0.49,19.25]$ & $P=0.23$ \\
\hline 24 h-mortality (non-RCT) & 3 & 831 & Not applicable & RR (M-H, Fixed, 95\% Cl) & $1.23[0.94,1.62]$ & $P=0.13$ \\
\hline 24 h-mortality (CPR) & 1 & 229 & Not applicable & RR (M-H, Fixed, 95\% Cl) & $1.23[0.94,1.62]$ & $P=0.13$ \\
\hline 24 h-mortality (non-CPR) & 5 & 1248 & $P=1.00 ; P^{2}=0 \%$ & RR (M-H, Fixed, 95\% Cl) & $3.06[0.49,19.25]$ & $P=0.23$ \\
\hline 24 h-mortality (experienced) & 1 & 164 & Not applicable & RR (M-H, Fixed, 95\% Cl) & $3.07[0.13,74.35]$ & $P=0.49$ \\
\hline $24 \mathrm{~h}$-mortality (inexperienced) & 5 & 1313 & $P=0.73 ; P^{2}=0 \%$ & RR (M-H, Fixed, 95\% Cl) & $1.27[0.97,1.67]$ & $P=0.08$ \\
\hline $28 d$-mortality & 7 & 1821 & $P=0.98 ; P^{2}=0 \%$ & RR (M-H, Fixed, 95\% Cl) & $1.04[0.92,1.19]$ & $P=0.52$ \\
\hline 28 d-mortality $(\mathrm{RCT})$ & 5 & 1382 & $P=0.90 ; P^{2}=0 \%$ & RR (M-H, Fixed, 95\% Cl) & $1.04[0.86,1.26]$ & $P=0.66$ \\
\hline $28 \mathrm{~d}$-mortality (non-RCT) & 2 & 439 & $P=0.82 ; P^{2}=0 \%$ & RR (M-H, Fixed, 95\% Cl) & $1.04[0.88,1.23]$ & $P=0.62$ \\
\hline 28 d-mortality (CPR) & 1 & 229 & Not applicable & RR (M-H, Fixed, 95\% Cl) & $1.03[0.86,1.23]$ & $P=0.76$ \\
\hline 28 d-mortality (non-CPR) & 6 & 1592 & $P=0.95 ; P^{2}=0 \%$ & RR (M-H, Fixed, 95\% Cl) & $1.05[0.89,1.24]$ & $P=0.57$ \\
\hline $28 \mathrm{~d}$-mortality (experienced) & 2 & 821 & $P=0.94 ; I^{2}=0 \%$ & RR (M-H, Fixed, 95\% Cl) & $1.22[0.83,1.79]$ & $P=0.32$ \\
\hline $28 \mathrm{~d}$-mortality (inexperienced) & 5 & 1000 & $P=0.99 ; P^{2}=0 \%$ & RR (M-H, Fixed, 95\% Cl) & $1.01[0.88,1.16]$ & $P=0.88$ \\
\hline
\end{tabular}


secretions and emesis in the upper airway, which are common during the CPR, leading to a longer duration of intubation which may worsen the patient's prognosis $[16,22]$. Besides traditional airway suctioning, other techniques to decrease influences of massive secretions and emesis on airway visualization and intubation procedure, such as intentional esophageal intubation (IEI) [45] and suction-assisted laryngoscopy and airway decontamination (SALAD) [46], have been described. Furthermore, the use of airway decontamination technique provides improved intubation conditions with a VL. However, these methods appear mostly in case report or simulated mannequin study and have not been generalized in clinical practice. Nowadays, even for skilled operators like trained anesthesiologists, DL might still be the first choice for urgent tracheal intubation during the $\mathrm{CPR}$, especially in patients without difficult airways.

Our study included RCTs and observational studies. The overall risk assessment of bias for the included RCTs was classified as low risk. Although blinding was not adopted in the most RCTs, we judged "no blinding" as low risk, as it seems impossible to blind personnel in the urgent situations at times. The overall risk assessment of bias for the included observational studies was classified as moderate or severe risk, mainly due to the confounding factors. For most outcomes, the level of heterogeneity was low, but subgroup and sensitivity analyses based on some potential clinical heterogeneous factors had been performed in our analysis. Furthermore, the TSA ensured the credibility of the result of primary endpoint from RCTs.

There are some limitations in our analysis that deserve special attentions. First and foremost, the inclusion of observational studies inevitably introduces selection bias, leading the possibility that patients in the VL and DL groups differ significantly in terms of operator's expertise, anesthesia methods, certain difficult airway characteristics, clinical scenarios, and even basic characteristics of patients [4-6, 8-10]. Besides the disparities between groups, a reporting bias might be also present due to self-reported or recall property of the data in the observational studies, leading to the inaccuracy of data collection. Second, some of the included studies were qualityimprovement process within a before-after study $[4,9]$. The better result may probably not only from the switch from DL to VL, but also from the improved patient management in quality-improvement studies. Third, during the searching process, 12 observational studies were found to be carried out in a same ED or ICU from a same hospital with an overlapped study period $[3,5$, $10,47-55]$. Only the latest 3 large studies $[3,5,10]$ covering the majority of other 8 studies were decided to be included. This might lose some validated participants while avoiding repeated enrolment. Fourth, definition of the expertise used in our analysis was somewhat arbitrary. A Cochrane review defines an experienced operator as a clinician with more than 20 tracheal intubations with each device and thence obtains a fewer failed intubations when using VL [56]. However, it is suggested that the number of procedures required to achieve proficiency with tracheal intubation using DL in an controlled environment like OR is approximately 50 $[57,58]$. Given the challenges of limited cardiopulmonary reserve, difficulty on airway assessment, few chances of tracheal intubation practice in the ED or $\mathrm{ICU}$, it is even hard to know how many procedures are required to achieve a definitive competence with tracheal intubation in this patient population. Anyhow, having one VL available for all urgent tracheal intubation could potentially offer a major safety advantage. Fifth, there might be still some other heterogeneous factors in our analysis, such as different types of VLs used and different in-hospital setting, i.e. ED, ICU, or general ward. About one third of our included studies used more than one type of VL $[3-5,8,10,17,19]$, making subgroup analysis on this factor difficult. Although ED and ICU are two main in-hospital settings for urgent tracheal intubation, indications, intubation conditions, and severity of patients' illness would not differ significantly, at least not as much as the difference between prehospital and in-hospital setting. Lastly, some studies used the episode of intubations or attempts instead of participants $[3,4,12]$. When calculating incidence of adverse outcomes, this would be inappropriate. However, sensitivity analysis by excluding these studies did not change the result of primary endpoint.

\section{Conclusions}

This systematic review and meta-analysis reveals that VL can reduce the risk of EI during urgent tracheal intubations in the ED and ICU patients, but does not provide significant benefits on other adverse events associated with tracheal intubation. Further studies are needed to demonstrate whether severe adverse events like cardiac arrest or mortality are significantly different between two devices. Furthermore, well-designed RCTs are further needed to focus on a specific scenario and should stratify some other prognostic indicators such as length of hospital stay and cost.

\section{Supplementary information}

Supplementary information accompanies this paper at https://doi.org/10. 1186/s13049-020-0702-7.

Additional file 1: Fig. S1-S20. The funnel plot obtained from primary outcome. Fig. S2. Forest plot for comparison of rate of esophageal intubation between video laryngoscope $(\mathrm{VL})$ and direct laryngoscope (DL). M-H, Mantel-Haenszel. Fig. S3. Forest plot for comparison of rate of esophageal intubation based on whether a CPR study between video 
laryngoscope (VL) and direct laryngoscope (DL). M-H, Mantel-Haenszel. Fig. S4. Forest plot for comparison of rate of esophageal intubation based on experience of operators between video laryngoscope $(\mathrm{VL})$ and direct laryngoscope (DL). M-H, Mantel-Haenszel. Fig. S5. Forest plot for comparison of incidence of hypoxemia based on the type of studies between video laryngoscope $(\mathrm{VL})$ and direct laryngoscope (DL). $\mathrm{M}-\mathrm{H}$, Mantel-Haenszel. Fig. S6. Forest plot for comparison of incidence of hypoxemia based on experience of operators between video lanyngoscope (VL) and direct laryngoscope (DL). M-H, Mantel-Haenszel. Fig. S7. Forest plot for comparison of incidence of severe hypoxemia based on the type of studies between video laryngoscope (VL) and direct laryngoscope (DL). M- $\mathrm{H}_{\text {, }}$ Mantel-Haenszel. Fig. S8. Forest plot for comparison of incidence of severe hypoxemia based on experience of operators between video laryngoscope (VL) and direct laryngoscope (DL). M-H, Mantel-Haenszel. Fig. S9. Forest plot for comparison of incidence of aspiration based on the type of studies between video laryngoscope (VL) and direct laryngoscope (DL). M-H, Mantel-Haenszel. Fig. S10. Forest plot for comparison of incidence of aspiration based on whether a CPR study between video laryngoscope (VL) and direct laryngoscope (DL). M-H, Mantel-Haenszel. Fig. S11. Forest plot for comparison of incidence of aspiration based on experience of operators between video laryngoscope (VL) and direct laryngoscope (DL). M-H, Mantel-Haenszel. Fig. S12. Forest plot for comparison of incidence of new onset of cardiac arrest based on the type of studies between video laryngoscope (VL) and direct laryngoscope (DL). M-H, Mantel-Haenszel. Fig. S13. Forest plot for comparison of incidence of new onset of cardiac arrest based on experience of operators between video laryngoscope $(\mathrm{VL})$ and direct laryngoscope (DL). M-H, Mantel-Haenszel. Fig. S14. Forest plot for comparison of $24 \mathrm{~h}$-mortality based on the type of studies between video laryngoscope (VL) and direct laryngoscope (DL). M-H, Mantel-Haenszel. Fig. S15. Forest plot for comparison of $24 \mathrm{~h}$-mortality based on whether a CPR study between video laryngoscope (VL) and direct laryngoscope (DL). M-H, Mantel-Haenszel. Fig. S16. Forest plot for comparison of $24 \mathrm{~h}$-mortality based on experience of operators between video laryngoscope $(\mathrm{VL})$ and direct laryngoscope (DL). M-H, Mantel-Haenszel. Fig. S17. Forest plot for comparison of $28 \mathrm{~d}$-mortality based on the type of studies between video laryngoscope (VL) and direct laryngoscope (DL). M-H, Mantel-Haenszel. Fig. S18. Forest plot for comparison of $28 \mathrm{~d}$-mortality based on whether a CPR study between video laryngoscope (VL) and direct laryngoscope (DL). M-H, Mantel-Haenszel. Fig. S19. Forest plot for comparison of $28 \mathrm{~d}$-mortality based on experience of operators between video laryngoscope (VL) and direct laryngoscope (DL). M-H, Mantel-Haenszel. Fig. S20. The TSA for (a) rate of esophageal intubation, (b) incidence of hypoxemia, (c) incidence of severe hypoxemia, (d) incidence of aspiration, (e) incidence of new-onset cardiac arrest, (f) $24 \mathrm{~h}$-mortality, (g) $28 \mathrm{~d}$-mortality based on 5\% risk of type-1 error (one-sided upper), power $80 \%$, low bias-based relative risk reduction and incidence in control arm with a model variance-based heterogeneity correction.

Additional file 2: Tables S1-S2. The GRADE for all adverse events. The TSA for all adverse events from randomized controlled trials.

\section{Acknowledgements}

The authors acknowledge the Cochrane Collaboration for quidance on implementing this analysis. The authors acknowledge Professor J. Salkes for providing additional information, and Professors S. Zhao and Z. R. Zhou for their professional advices in the risk bias assessment and statistical analyses.

\section{Authors' contributions}

$\mathrm{JJ}$ and NK significantly contributed to the design and implementation of the study, as well as analysis and interpretation, and they drafted the manuscript. BL participated substantially in data acquisition and interpretation. ASW contributed considerably to the conception and design of the study, supervised implementation of the study, performed data analysis and interpretation, and wrote the manuscript. FSX significantly contributed to the conception of the study, performed data analysis and interpretation, and critically revised the manuscript. All authors saw the original study data, reviewed the analysis of the data, and read and approved the final manuscript.

\section{Funding}

None.

\section{Availability of data and materials}

All data generated or analyzed during this study are included in this published article.

\section{Ethics approval and consent to participate}

This study did not need ethical approval and consent from any patients involved in the study was also not needed.

\section{Consent for publication}

Not applicable.

\section{Competing interests}

The authors declare they have no competing interests.

\section{Author details}

'Department of Anesthesiology, Beijing Chaoyang Hospital, Capital Medical University, Beijing 100020, China. ${ }^{2}$ Beijing Hospital of Traditional Chinese Medicine, Capital Medical University, Beijing Institute of Traditional Chinese Medicine, Beijing 100010, China. ${ }^{3}$ Department of Anesthesiology, Beijing Friendship Hospital, Capital Medical University, Beijing 100050, China.

Received: 3 September 2019 Accepted: 13 January 2020

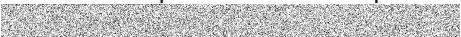

\section{References}

1. Cook TM, Woodall N, Harper J. Benger J; fourth National Audit Project. Major complications of airway management in the UK: results of the fourth National Audit Project of the Royal College of Anaesthetists and the difficult airway society. Part 2: intensive care and emergency departments. Br J Anaesth. 2011;106(5):632-42.

2. Jaber S, Amraoui J, Lefrant JY, Arich C, Cohendy R, Landreau L, et al. Clinical practice and risk factors for immediate complications of endotracheal intubation in the intensive care unit: a prospective, multiple-center study. Crit Care Med. 2006;34(9):2355-61.

3. Sakles JC, Javedani PP, Chase E, Garst-Orozco J, Guillen-Rodriguez JM, Stolz $\mathrm{U}$. The use of a video laryngoscope by emergency medicine residents is associated with a reduction in esophageal intubations in the emergency department. Acad Emerg Med. 2015;22(6):700-7.

4. De Jong A, Clavieras N, Conseil M, Coisel Y, Moury PH, Pouzeratte Y, et al. Implementation of a combo videolaryngoscope for intubation in critically ill patients: a before-after comparative study. Intensive Care Med. 2013;39(12): 2144-52.

5. Hypes CD, Stolz U, Sakles JC, Joshi RR, Natt B, Malo J, et al. Video laryngoscopy improves odds of first-attempt success at intubation in the intensive care unit. A propensity-matched analysis. Ann Am Thorac Soc. 2016:13(3):382-90.

6. Kory P, Guevarra K, Mathew JP, Hegde A, Mayo PH. The impact of video laryngoscopy use during urgent endotracheal intubation in the critically ill. Anesth Analg. 2013;117(1):144-9.

7. Lakticova V, Koenig SJ, Narasimhan M, Mayo PH. Video laryngoscopy is associated with increased first pass success and decreased rate of esophageal intubations during urgent endotracheal intubation in a medical intensive care unit when compared to direct laryngoscopy. I Intensive Care Med. 2015;30(1):44-8.

8. Lee DH, Han M, An JY, Jung JY, Koh Y, Lim CM, et al. Video laryngoscopy versus direct laryngoscopy for tracheal intubation during in-hospital cardiopulmonary resuscitation. Resuscitation. 2015:89:195-9.

9. Noppens RR, Geimer S, Eisel N, David M, Piepho T. Endotracheal intubation using the C-MAC video laryngoscope or the Macintosh laryngoscope: a prospective, comparative study in the ICU. Crit Care. 2012;16(3):R103.

10. Okamoto H, Goto T, Wong ZSY, Hagiwara Y, Watase H, Hasegawa K: Japanese Emergency Medicine Network investigators. Comparison of video laryngoscopy versus direct laryngoscopy for intubation in emergency department patients with cardiac arrest: a multicentre study. Resuscitation 2019; 136:70-77.

11. Park SO, Kim JW, Na JH, Lee KH, Lee KR, Hong DY, Baek KJ. Video laryngoscopy improves the first-attempt success in endotracheal intubation during cardiopulmonary resuscitation among novice physicians. Resuscitation. 2015;89:188-94. 
12. Vassiliadis J, Tzannes A, Hitos K, Brimble J, Fogg T. Comparison of the CMAC video laryngoscope with direct Macintosh laryngoscopy in the emergency department. Emerg Med Australas. 2015;27(2):119-25.

13. Driver B, Prekker M, Moore J, Schick AL, Reardon RF, Miner JR. Direct versus video laryngoscopy using the C-MAC for tracheal intubation in the emergency department, a randomized controlled trial. Acad Emerg Med. 2016;23(4):433-9.

14. Gao YX, Song YB, Gu ZJ, Zhang JS, Chen XF, Sun H, Lu Z. Video versus direct laryngoscopy on successful first pass endotracheal intubation in ICU patients. World J Emerg Med. 2018;9(2):99-104.

15. Goksu E, Kilic T, Yildiz G, Unal A, Kartal M. Comparison of the C-MAC video laryngoscope to the Macintosh laryngoscope for intubation of blunt trauma patients in the ED. Turk J Emerg Med. 2016;16(2):53-6.

16. Griesdale D, Chau A, Isac G, Ayas N, Foster D, Irwin C. Choi P; Canadian critical care trials group. Video-laryngoscopy versus direct laryngoscopy in critically ill patients: a pilot randomized trial. Can J Anesth. 2012;59(11): 1032-9.

17. Janz DR, Semler MW, Lentz RJ, Matthews DT, Assad TR, Norman BC. Et al; facilitating EndotracheaL intubation by laryngoscopy technique and apneic oxygenation within the ICU investigators and the pragmatic critical care research group. Randomized trial of video laryngoscopy for endotracheal intubation of critically ill adults. Crit Care Med. 2016;44(11):1980-7.

18. Kim J, Park S, Lee K, Hong DY, Baek KJ, Lee YH, et al. Video laryngoscopy vs. direct laryngoscopy: which should be chosen for endotracheal intubation during cardiopulmonary resuscitation? A prospective randomized controlled study of experienced intubators. Resuscitation 2016; 105: 196-202.

19. Lascarrou J, Boisrame-Helms J, Bailly A, Le Thuaut A, Kamel T, Mercier E. Et al; clinical research in intensive care and Sepsis (CRICS) group. Video laryngoscopy vs direct laryngoscopy on successful first-pass Orotracheal intubation among ICU patients: a randomized clinical trial. JAMA. 2017; 317(5):483-93.

20. Silverberg MJ, Li N, Acquah SO, Kory PD. Comparison of video laryngoscopy versus direct laryngoscopy during urgent endotracheal intubation: a randomized controlled trial. Crit Care Med. 2015;43(3):636-41.

21. Sulser S, Ubmann D, Schlaepfer M, Brueesch M, Goliasch G, Seifert B, et al. C-MAC videolaryngoscope compared with direct laryngoscopy for rapid sequence intubation in an emergency department: a randomised clinical trial. Eur J Anaesthesiol. 2016;33(12):943-8.

22. Yeatts DJ, Dutton RP, Hu PF, Chang YW, Brown CH, Chen H, et al. Effect of video laryngoscopy on trauma patient survival: a randomized controlled trial. J Trauma Acute Care Surg. 2013;75(2):212-9.

23. Jiang J, Ma D, Li B, Yue Y, Xue F. Video laryngoscopy does not improve the intubation outcomes in emergency and critical patients-a systematic review and meta-analysis of randomized controlled trials. Crit Care. 2017;21(1):288.

24. Arulkumaran N, Lowe J, lons R, Mendoza M, Bennett V, Dunser MW. Videolaryngoscopy versus direct laryngoscopy for emergency orotracheal intubation outside the operating room: a systematic review and metaanalysis. Br J Anaesth. 2018;120(4):712-24.

25. Savino PB, Reichelderfer S, Mercer MP, Wang RC, Sporer KA. Direct versus video laryngoscopy for Prehospital intubation: a systematic review and Meta-analysis. Acad Emerg Med. 2017;24(8):1018-26.

26. Bhattacharjee S, Maitra S, Baidya DK. A comparison between video laryngoscopy and direct laryngoscopy for endotracheal intubation in the emergency department: a meta-analysis of randomized controlled trials. J Clin Anesth. 2018;47:21-6.

27. Zhao BC, Huang TY, Liu KX. Video laryngoscopy for ICU intubation: a metaanalysis of randomised trials. Intensive Care Med. 2017:43(6):947-8.

28. Huang HB, Peng JM, Xu B, Liu GY, Du B. Video laryngoscopy for endotracheal intubation of critically ill adults: a systemic review and Metaanalysis. Chest. 2017;152(3):510-7.

29. De Jong A, Molinari N, Conseil M, Coisel Y, Pouzeratte Y, Belafia F, et al. Video laryngoscopy versus direct laryngoscopy for orotracheal intubation in the intensive care unit: a systematic review and meta-analysis. Intensive Care Med. 2014:40(5):629-39.

30. Moher D, Liberati A, Tetzlaff J. Altman DG; PRISMA group. Preferred reporting items for systematic reviews and meta-analyses: the PRISMA statement. J Clin Epidemiol. 2009;62(10):1006-12.

31. Shamseer L, Moher D, Clarke M, Ghersi D, Liberati A, Petticrew M, et al; PRISMA-P Group. Preferred reporting items for systematic review and metaanalysis protocols (PRISMA-P) 2015: elaboration and explanation. BMJ 2015; 350: g7647.
32. Cochrane: HJG. Cochrane handbook for systematic reviews of interventions version 5.1[updated March 2011] [last accessed on 15.6.2015]: The Cochrane collaboration. 2011. www.cochrane-handbook.org

33. Sterne J, Higgins J, Reeves B, editors. A Cochrane risk of bias assessment tool: for non-randomized studies of interventions (ACROBAT-NRSI), vol. 24; 2014. Available from: Version1.0.0. http://www.riskofbias.info. Accessed on $01 / 11 / 2017$

34. Egger M, Davey Smith G, Schneider M, Minder C. Bias in meta-analysis detected by a simple, graphical test. BMJ. 1997;315(7109):629-34.

35. Guyatt G, Oxman AD, Akl EA, Kunz R, Vist G, Brozek J, et al. GRADE guidelines: 1. Introduction-GRADE evidence profiles and summary of findings tables. J Clin Epidemiol. 2011;64(4):383-94.

36. Guyatt GH, Oxman AD, Kunz R, Vist GE, Falck-Ytter Y. Schünemann HJ; GRADE working group. What is "quality of evidence" and why is it important to clinicians? BMJ. 2008;336(7651):995-8.

37. Brok J, Thorlund K, Wetterslev J, Gluud C. Apparently conclusive meta-analyses may be inconclusive--trial sequential analysis adjustment of random error risk due to repetitive testing of accumulating data in apparently conclusive neonatal meta-analyses. Int J Epidemiol. 2009;38(1):287-98.

38. TSA: Trial Sequential Analysis Viewer (TSA Viewer) [Computer program]. Version 0.9.5.10 Beta. Copenhagen: Copenhagen Trial Unit, Centre for Clinical Intervention Research, Rigshospitalet, 2016.

39. Khandelwal N, Galgon RE, Ali M, Joffe AM. Cardiac arrest is a predictor of difficult tracheal intubation independent of operator experience in hospitalized patients. BMC Anesthesiol. 2014;14:38.

40. Driver BE, Klein LR, Schick AL, Prekker ME, Reardon RF, Miner JR. The occurrence of aspiration pneumonia after emergency endotracheal intubation. Am J Emerg Med. 2018;36(2):193-6.

41. Platts-Mills TF, Campagne D, Chinnock B, Snowden B, Glickman LT, Hendey GW. A comparison of GlideScope video laryngoscopy versus direct laryngoscopy intubation in the emergency department. Acad Emerg Med. 2009;16(9):866-71.

42. Paolini JB, Donati F, Drolet P. Review article: video-laryngoscopy: another tool for difficult intubation or a new paradigm in airway management? Can J Anaesth. 2013;60(2):184-91.

43. Kleine-Brueggeney M, Greif R, Schoettker P, Savoldelli GL, Nabecker S, Theiler LG. Evaluation of six videolaryngoscopes in 720 patients with a simulated difficult airway: a multicentre randomized controlled trial. $\mathrm{Br}$ J Anaesth. 2016;116(5):670-9.

44. van Zundert A, Pieters B, Doerges V, Gatt S. Videolaryngoscopy allows a better view of the pharynx and larynx than classic laryngoscopy. $\mathrm{Br} J$ Anaesth. 2012;109(6):1014-5.

45. Sorour K, Donovan L. Intentional esophageal intubation to improve visualization during emergent endotracheal intubation in the context of massive vomiting: a case report. J Clin Anesth. 2015;27(2):168-9.

46. DuCanto J, Serrano KD, Thompson RJ. Novel airway training tool that simulates vomiting: suction-assisted laryngoscopy assisted decontamination (SALAD) system. West J Emerg Med. 2017;18(1):117-20.

47. Mosier JM, Whitmore SP, Bloom JW, Snyder LS, Graham LA, Carr GE, Sakles JC. Video laryngoscopy improves intubation success and reduces esophageal intubations compared to direct laryngoscopy in the medical intensive care unit. Crit Care. 2013;17:R237.

48. Michailidou M, O'Keeffe T, Mosier JM, Friese RS, Joseph B, Rhee P, Sakles JC. A comparison of video laryngoscopy to direct laryngoscopy for the emergency intubation of trauma patients. World J Surg. 2015;39(3):782-8.

49. Sakles JC, Mosier JM, Patanwala AE, Arcaris B, Dicken JM. The utility of the C-MAC as a direct laryngoscope for intubation in the emergency department. J Emerg Med 2016; 51(4): 349-357.

50. Sakles JC, Cosentino ML. Airway management in the emergency department: a comparison of CMAC video laryngoscopy to direct laryngoscopy. Acad Emerg Med. 2011;18:S35.

51. Sakles JC, Javedani PP, Jessica GO, Garst-Orozco J, Guillen-Rodriguez JM, Stolz U. Video laryngoscopy reduces the rate of esophageal intubations performed by emergency medicine residents compared to direct laryngoscopy. Acad Emerg Med. 2013;20:S297.

52. Sakles JC, Mosier J, Chiu S, Cosentino M, Kalin L. A comparison of the C-MAC video laryngoscope to the macintosh direct laryngoscope for intubation in the emergency department. Ann Emerg Med. 2012;60(6):739-48.

53. Sakles JC, Mosier JM, Chiu S, Keim SM. Tracheal intubation in the emergency department: a comparison of GlideScope ${ }^{\circledast}$ video laryngoscopy to direct laryngoscopy in 822 intubations. J Emerg Med. 2012;42(4):400-5. 
54. Sakles JC, Mosier JM, Patanwala AE, Dicken JM, Kalin L, Javedani PP. The C-MAC video laryngoscope is superior to the direct laryngoscope for the rescue of failed first-attempt intubations in the emergency department. J Emerg Med. 2015:48(3):280-6.

55. Shirakura Y, Okamoto H, Watase H, Hasegawa K. Video laryngoscopy does not improve the first pass success rate during cardiopulmonary

resuscitation in the emergency department: An analysis of multicenter observational study. Ann Emerg Med. 2015;66(4):S37.

56. Lewis SR, Butler AR, Parker J, Cook TM, Schofield-Robinson OJ, Smith AF. Videolaryngoscopy versus direct laryngoscopy for adult patients requiring tracheal intubation: a Cochrane systematic review. Br J Anaesth. 2017;119(3): 369-83

57. Mulcaster JT, Mills J, Hung OR, MacQuarrie K, Law JA, Pytka S, et al. Laryngoscopic intubation: learning and performance. Anesthesiology. 2003:98(1):23-7.

58. de Oliveira Filho GR. The construction of learning curves for basic skills in anesthetic procedures: an application for the cumulative sum method. Anesth Analg. 2002;95(2):411-6.

\section{Publisher's Note}

Springer Nature remains neutral with regard to jurisdictional claims in published maps and institutional affiliations.

Ready to submit your research? Choose BMC and benefit from:

- fast, convenient online submission

- thorough peer review by experienced researchers in your field

- rapid publication on acceptance

- support for research data, including large and complex data types

- gold Open Access which fosters wider collaboration and increased citations

- maximum visibility for your research: over $100 \mathrm{M}$ website views per year

At BMC, research is always in progress.

Learn more biomedcentral.com/submissions 